\title{
Corrigendum
}

\section{Corrigendum to "Effect of Glycyrrhiza on the Diuretic Function of Euphorbia kansui: An Ascites Mouse Model"}

\author{
Ya Lin ${ }^{\mathbb{D}},{ }^{1,2}$ Yanqiong Zhang $\left(\mathbb{D},{ }^{2}\right.$ Erxin Shang, ${ }^{3}$ Wenfang Lai, ${ }^{1}$ Hongwei Zhu, \\ Yuhua Fang, ${ }^{1}$ Qingxia Qin, ${ }^{1,2}$ Haiyu Zhao, ${ }^{2}$ and $\mathrm{Na}$ Lin $\mathbb{D}^{1,2}$ \\ ${ }^{1}$ College of Pharmacy, Fujian University of Traditional Chinese Medicine, Fuzhou 350122, China \\ ${ }^{2}$ Institute of Chinese Materia Medica, China Academy of Chinese Medical Sciences, Beijing 100700, China \\ ${ }^{3}$ Jiangsu Provincial Key Laboratory for Formulae Research, Nanjing University of Traditional Chinese Medicine, \\ Nanjing 210046, China \\ ${ }^{4}$ Wangjing Hospital, China Academy of Chinese Medical Sciences, Beijing 100102, China \\ Correspondence should be addressed to Na Lin; nlin@icmm.ac.cn
}

Received 14 October 2018; Accepted 15 October 2018; Published 16 December 2018

Copyright (C) 2018 Ya Lin et al. This is an open access article distributed under the Creative Commons Attribution License, which permits unrestricted use, distribution, and reproduction in any medium, provided the original work is properly cited.

In the article titled "Effect of Glycyrrhiza on the Diuretic Function of Euphorbia kansui: An Ascites Mouse Model" [1], there were two errors with the parameters in the regression equations. Therefore, the text reading "Ascites volume was defined by the stepwise equation, $Y_{1}=6.331 * X_{1}^{2} * X_{2}-$ $4.16 * X_{1}^{2}-0.1637 / X_{2}^{2}+10.94(r=0.9845, P=0.0091)$, displayed in Figure 3(a). Ascites volume/body weight of mice was defined as a dependent variable $Y_{2}$ using the multivariate stepwise regression equation $Y_{2}=0.06416 * X_{1} * X_{2}{ }^{2}-$ $0.006046 / X_{2}^{2}+0.3062(r=0.9479, P=0.0103)$ as shown in Figure 4(a)." should be corrected to

"Ascites volume was defined by the stepwise equation, $Y_{1}=6.331 * X_{1}{ }^{2} * X_{2}-4.16 * X_{1}{ }^{2}-0.1637 / X_{2}^{2}+11.62$ $(r=0.9845, P=0.0091)$, displayed in Figure 3(a). Ascites volume/body weight of mice was defined as a dependent variable $Y_{2}$ using the multivariate stepwise regression equation $Y_{2}=0.06416 * X_{1} * X_{2}{ }^{2}-0.006046 / X_{2}{ }^{2}+0.4288(r=0.9479$, $P=0.0103)$ as shown in Figure 4(a)."

In addition, the photograph of the renal pathological changes in the Furosemide group in Figure 7(b)-Furo was misplaced. The corrected version of the figure with its description is shown below: 

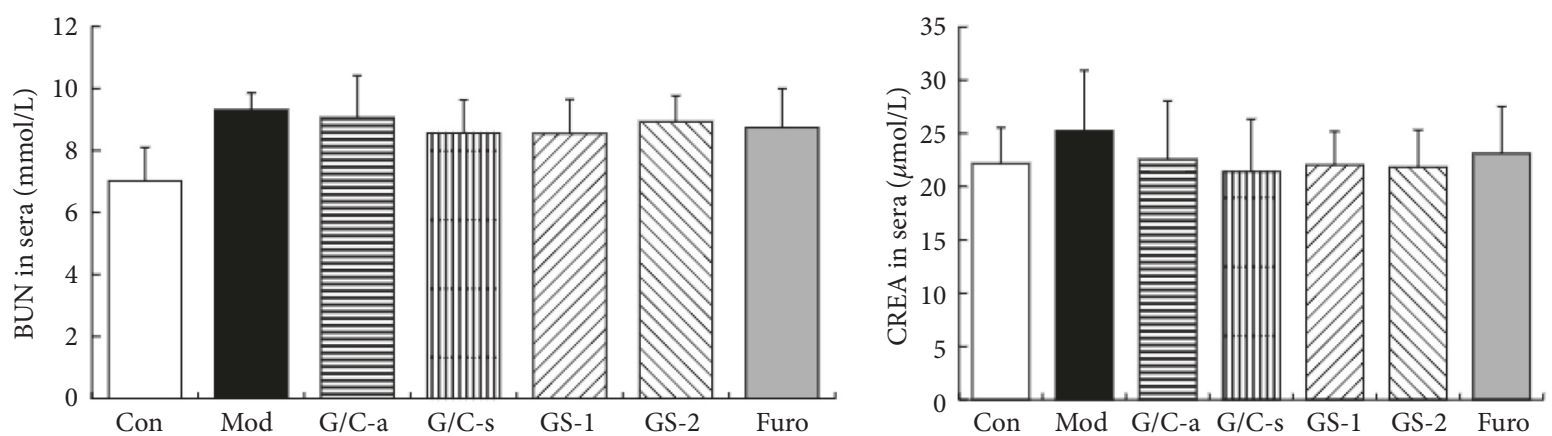

(a)
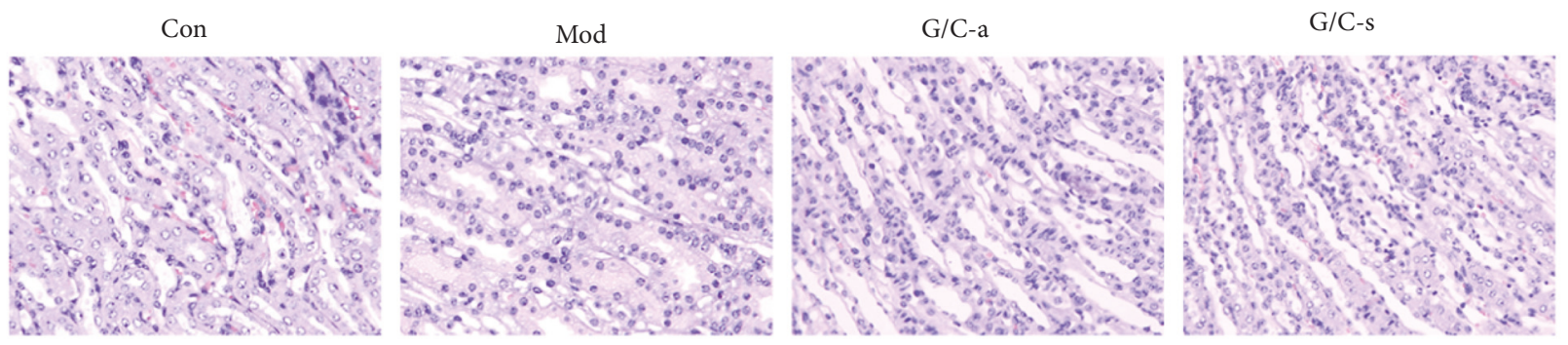

GS-1

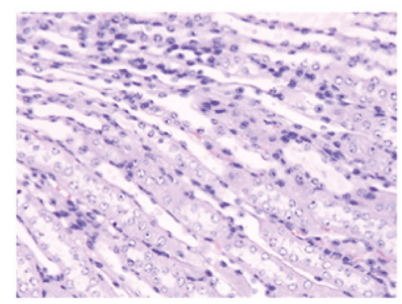

GS-2

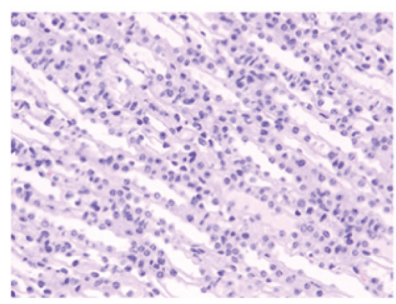

Furo

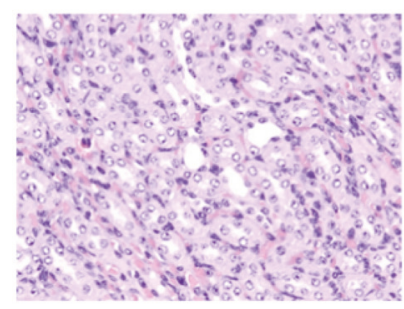

(b)

Figure 7: Renal toxicity in H22 HCC ascites mice. (a) Serum levels of BUN and CREA were not altered significantly in any treatment groups. (b) No specific pathological symptoms were detected in different groups. Most kidney cells retained normal structure, without any degeneration or necrosis and edema or swelling of glomerulus and renal tubules. Hematoxylin-eosin (H\&E) staining, 400× magnification.

\section{References}

[1] Y. Lin, Y. Zhang, E. Shang et al., "Effect of Glycyrrhiza on the diuretic function of Euphorbia kansui: an ascites mouse model," Evidence-Based Complementary and Alternative Medicine, vol. 2016, Article ID 7620817, 13 pages, 2016. 


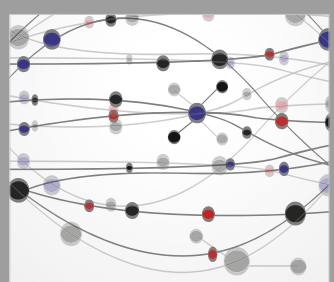

The Scientific World Journal
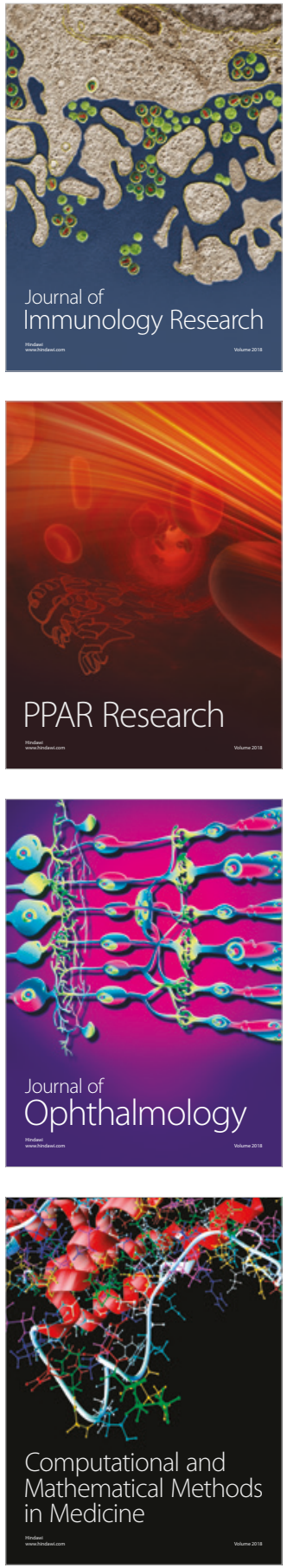

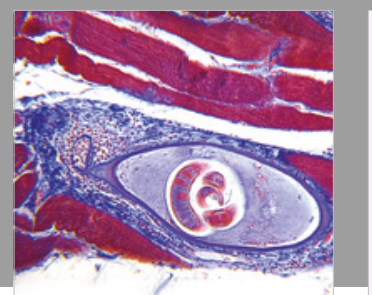

Gastroenterology Research and Practice

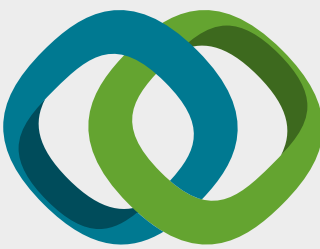

\section{Hindawi}

Submit your manuscripts at

www.hindawi.com
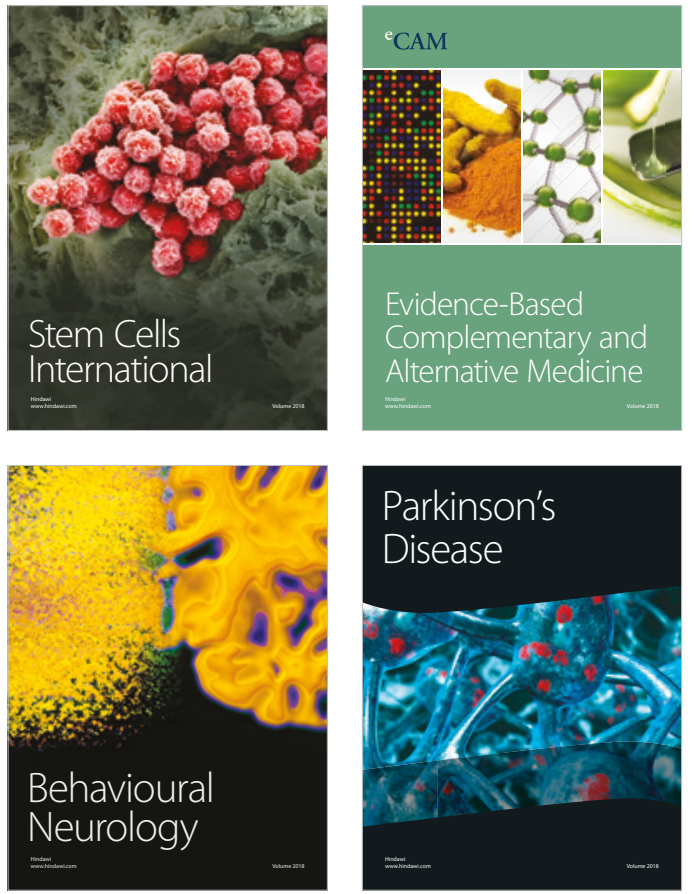

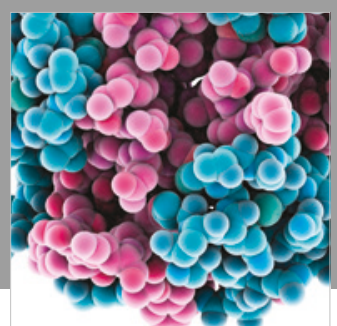

ournal of

Diabetes Research

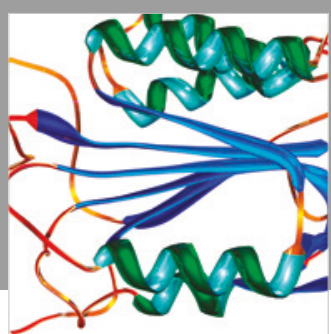

Disease Markers
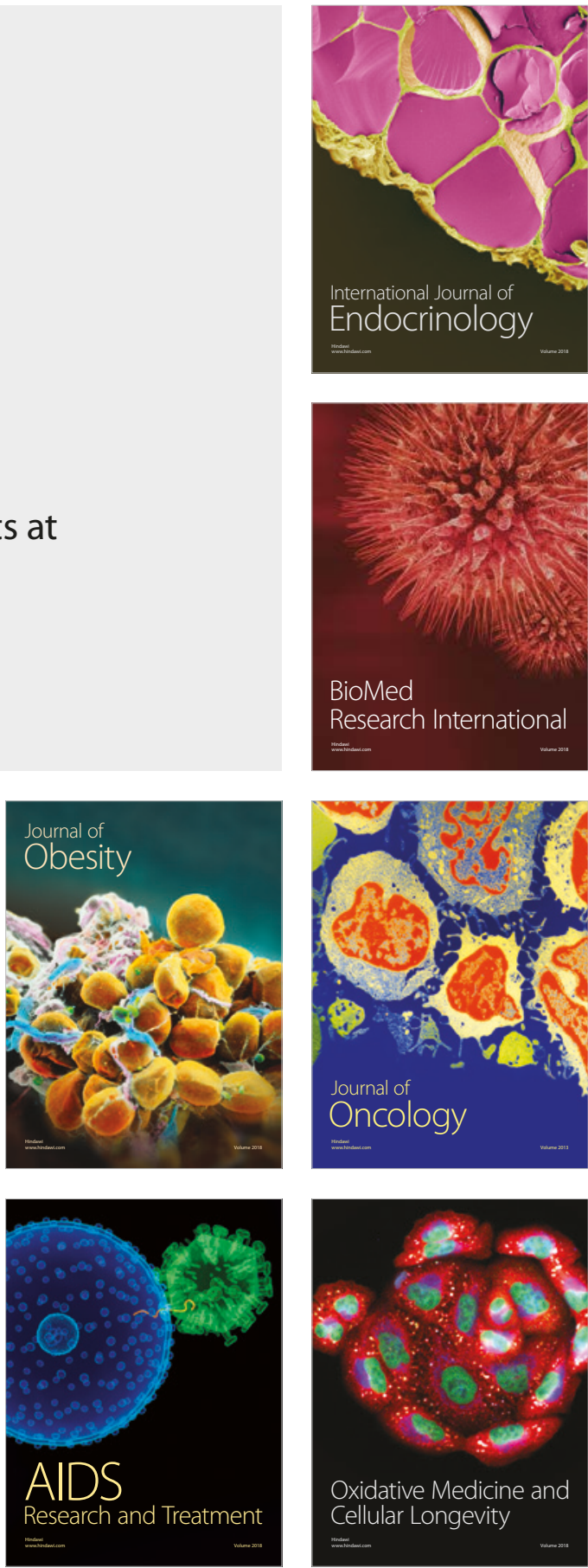